\title{
Design Principles, Challenges, and the Future of Employment in the Context of Industry 4.0: A Review
}

\author{
V. R. Mishra
}

Department of Mechanical Engineering, GLBITM, Greater Noida - 201306, Uttar Pradesh, India; hod.me@glbitm.org

\begin{abstract}
Objectives: Industry 4.0 is a term used to hint the upgrade procedure in the association of social affair and chainage. The term likewise implies the fourth present rebellion. The term Industry 4.0 was first transparently shown in 2011 as "Industry 4.0 " by a party of administrators from various fields, (for example, business, restorative, authoritative issues, and the scholarly system) under an activity to upgrade the German forcefulness in the accumulating business. Methods/ Statistical Analysis: The German national government got the thought in its High-Tech Strategy for 2020. Along these lines, a Working Group was limited to likewise exhort on the usage concerning Industry 4.0. In 2003, they made and dispersed their first plan of recommendations. Their vision incorporated that these Cyber-Physical Systems join intelligent machines, putting away structures and age work environments prepared to do self-regulating trading data, starting activities and controlling each other self-overseeing. Findings: This urges major moves up to the mechanical systems related to amassing, building, material use and generation system and life cycle the executives. Application: Industry 4.0 remains a term without a doubt comprehended in German-Industries. Accordingly, this guide will go for trying to describe the term, researching the arrangement gauges, the central focuses and the challenges standing up to such an approach, and endeavor to upgrade the potential.
\end{abstract}

Keywords: Challenges, Design, Employment, Industry 4.0, Principles, Zuture

\section{The History Behind Industry 4.0}

To have the ability to perceive how Industry 4.0 transformed into the present well-known articulation, a look at its trailblazers may give us a point of view on how this uprising explicitly is exceptional. The going with chart exhibits a course of occasions of the progression of amassing and the mechanical division. Shown in Figure 1 different modern upsets.

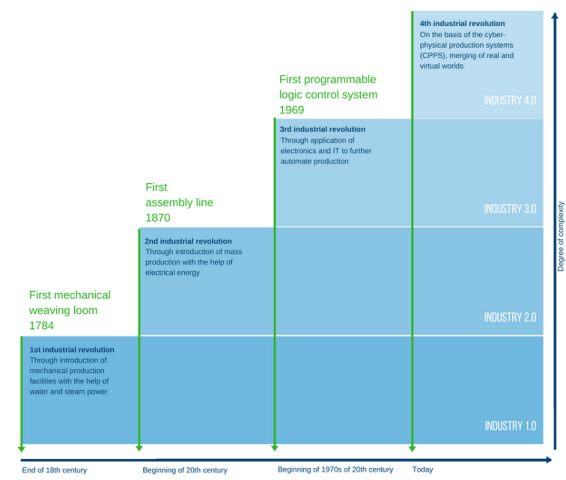

Figure 1. Various Industrial Revolutions

\section{The First Industrial Revolution}

The mechanical uprising in Britain came in to bring machines into creation before the total of the eighteenth century (1760-1840). It included going from manual age to the utilization of steam-filled motors and water as a wellspring of power. It aided developing inside and out and the enunciation "current office" changed into somewhat standard. One of the associations that profited a great deal from such changes is the material business and was the first to get such frameworks. It is like way set up a gigantic piece of the British economy at the time.

\section{The Second Industrial Revolution}

The mechanical uprising in Britain came in to bring machines into creation before the total of the eighteenth century (1760-1840). This included going from manual age to the utilization of steam-filled motors and water as a wellspring of intensity. It aided developing primarily 
and the verbalization "present day office" changed into somewhat standard. One of the associations that profited a ton from such changes is the material business and was the first to get such procedures. It also settled a large piece of the British economy at the time. Headways in science, for instance, the advancement of the produced shading, also check such period as science was in a genuinely harsh state by then. Nevertheless, such powerful ways to deal with overseeing industry is put to an end with the beginning of World War I. Colossal scale manufacturing, was not put to an end, yet slightly upgrades inside a near setting were made and none of which can be called present-day changes.

\section{The Third Industrial Revolution}

Possibly the third one is considerably more common to us than the rest as a large number of individuals living today think about endeavors slanting toward modernized headways in progress. Regardless, the third current revolt has dated someplace in the scope of 1950 and 1970. It is often implied as the Digital Revolution and happened as expected the change from straightforward and mechanical structures to cutting edge ones. Others think of it as the Information Age too. The third change was, and still is, a prompt outcome of the giant headway in PCs and information and correspondence advancement.

\section{Fourth Industrial Revolution: Difference from Earlier Revolutions}

The fourth current change takes the automation of collecting methodology to another measurement by showing adjusted and versatile broad scale fabricating advancements. Machines will work openly or partake with individuals in making a customer masterminded creation field that dependably wears down taking care of itself. The machine instead transforms into a free component that can accumulate data, explore it, and incite upon it. This winds up possible by introducing self-streamlining, self-wisdom, and self-customization into the business. The makers will have the ability to talk with PCs rather than work them.

\section{Cyber-Physical Systems}

As referenced more than, an advanced physical system goes for the joining of figuring and physical methods. PCs and frameworks can screen the physical methodology of gathering at a particular procedure 1 . The progression of such a structure involves three phases:

Distinguishing proof Unique, clear affirmation is central in gathering. This is the clear essential tongue by which a machine can give. RFID (Radio-rehash indisputable check) is a fantastic case of that. RFID utilizes an electromagnetic field to perceive an unequivocal name that is routinely added to a request. Even though such headway has been around since 1999, despite it fills in as a mind-blowing case of how Industry 4.0 worked at first.

The Integration of Sensors and Actuator: This is pivotal for a machine to work. The joining of sensors and actuators fundamentally surmises that an unequivocal machine's enhancement can be controlled and that it can perceive changes in nature. Regardless, even with the trade-off of sensors and actuators, their utilization was restricted and did not engage them to chat with one another.

The Development of Sensors and Actuators: Such movement enabled machines to store and dissect information. A CPS straightforwardly is outfitted with various sensors and actuators that can be made for the trading out of data.

\section{The Internet of Things (loT)}

An advanced physical structure still sounds reasonable to us today. Machines can exchange data and, in many employment, can identify the changes in the earth around them. Fire alarms are a certified instance of that. The Internet of Things, in any case, is accepted to be what indeed has begun Industry 4.0. The Internet of Things is what enables challenges and machines, for instance, mobile phones and sensors to "grant" with each other and also people to work out game plans. The blend of such advancement empowers articles to work and deal with issues self-sufficiently. This is not substantial as people are also allowed to mediate. the IoT can be described as a framework in which CPS take an interest with each other through exceptional tending to diagrams 2 . 


\section{The Internet of Services (loS)}

It is unquestionably not challenging to see that these days every single electronic gadget will without a doubt be connected with either another gadget or to the web. With the considerable upgrade and assembled arrangement in electronic and awesome gadgets, getting a more rough measure of them dynamically makes complexities and undermines the utility of every new contraption. Splendid telephones, tablets, workstations, TVs or even watches are twisting up continuously interconnected, at any rate, the more you purchase, the additional estimation of the last contraption winds up unrecognizable. The Internet of Services goes for making a wrapper that improves every single related gadget to make the most out of them by streamlining the technique. It is the client's area to the maker.

\section{Smart Factory}

Vigilant age lines are a vital segment of Industry 4.0. A sharp collecting plant gets an alleged Calm-framework ${ }^{3}$. A clear framework is a structure that can supervise both the physical world and what is more virtual. Such structures are assembled "foundation frameworks" and in a course work behind the scene. A quiet structure considers the including condition and the articles around it. It additionally can be upheld with touchy data concerning the request being made, for example, portrayals and models. "the Smart Factory can be depicted as a creation line where CPS ignore on the IoT and help individuals and machines in the execution of their undertakings".

\section{Industry 4.0 Design Principles}

The arrangement principles empower creators to look into a potential change to Industry 4.0 headways. In light of the parts over, coming up next are the arrangement guidelines:

Interoperability: Objects, machines, and people ought to have the ability to pass on through the Internet of Things and the Internet of People. This is the most fundamental standard that genuinely makes an assembling plant a splendid one.

Virtualization: CPSs must have the ability to recreate and make a virtual copy of this present reality. CPSs ought to in like manner can screen objects existing in the incorporating condition. Fundamentally, there must be a virtual copy of everything.
Decentralization: The limit of CPSs to work unreservedly. This gives space for adjusted things and basic reasoning. This is like manner makes an inexorably versatile condition for creation. In cases of frustration or having different targets, the issue is assigned to a more significant sum. In any case, even with such advances executed, the necessity for quality insistence remains a need all in all procedure ${ }^{3}$.

Continuous Capability: A sharp generation line ought to have the ability to assemble consistent data, store or examine it, and settle on decisions as demonstrated by new disclosures. This is not merely limited to measurable studying yet notwithstanding internal methodology, for instance, the mistake of a machine in progress line. Splendid things must have the ability to recognize the flaw and re-delegate errands to other working machines. This is like manner contributes hugely to the versatility and the headway of age.

Administration Orientation: Production must be customer arranged. People and sharp articles/ contraptions must have the ability to interface capably through the Internet of Services to make things subject to the customer's determinations ${ }^{4}$. This is the place the Internet of Services ends up essential. Particularity: In a dynamic market, a Smart Factory's ability to conform to another market is essential. In an ordinary case, it would probably take seven days for an ordinary association to contemplate the market and change its age as necessities are. Of course, sharp assembling plants must have the ability to alter snappily and effectively to standard changes and market designs.

\section{The Benefits and the Challenges}

Industry 4.0 will genuinely change how delivering shapes work. Regardless, it is essential to measure the excellent conditions and the challenges that associations may face.

\section{Central Purposes of Industry 4.0}

Streamlining: Optimizing creation is an excellent critical position for Industry 4.0. A Smart Factory contains hundreds or even countless Devices that can selfstreamline age will incite a practically zero downtime in progress. This is basic for organizations that usage top 
notch expensive amassing gear, for instance, the semiconductors industry.

Customization: Creating a ready market that is customer organized will help address the masses' issues brisk and easily ${ }^{5}$. It will in like manner pummel the opening between the producer and the customer. Correspondence will happen between both. Producers will not have to pass on inside (in associations and mechanical offices) and remotely (to customers). This appends the age and transport frames.

Pushing Research: The determination of Industry 4.0 advances will drive investigate in various fields, for instance, IT security and will have its effect on the guidance explicitly. Another industry will require another game plan of capacities. Hence, guidance and planning will take another shape that gives such an industry will the required talented work.

\section{Difficulties Confronting Industry 4.0}

Security: Perhaps the most troublesome piece of executing Industry 4.0 techniques is the IT security possibility. This online compromise will offer space to security and data spills. Computerized theft should in like manner be put into thought. For this circumstance, the issue is not individual, yet can, and apparently will, cost creators money and may even hurt their reputation. Along these lines, investigate in security is basic.

Capital: Such change will require a gigantic enthusiasm for another development that does not sound terrible. The decision to roll out such improvement ought to be on CEO level. Furthermore, still, after all that, the perils must be resolved and thought about critical. Besides, such change will require significant capital, which separations tinier associations and might cost them their bit of the general business later on.

Work: While despite all that it remains in front of the timetable to evaluate on business conditions with the determination of Industry 4.0 surrounding, it is ensured to express that worker ought to get remarkable or an all-new game plan of aptitudes. This may help business rates go up anyway it will similarly alienate noteworthy part workers. The section of authorities whose work is perhaps troubling will go up against a test in remaining mindful of the business. Different kinds of guidance must be displayed, anyway despite all that it does not deal with the issue for the senior piece of authorities. This is an issue that may set aside more significant opportunity to comprehend and will be moreover penniless down later in this report. Privacy: This is client's worry, as well as the makers. In such an interconnected industry, makers need to gather and examine information. To the client, this may resemble a danger to his protection. This is not just selective to shoppers. Little or vast organizations who have not shared their information in the past should work their way to an increasingly straightforward condition. Conquering any hindrance between the shopper and the maker will be a tremendous test for the two gatherings.

\section{The Future Workforce}

Industry 4.0 has a ton to ensure concerning livelihoods, theory, and creative degrees of progress, yet business remains a champion among the most shrouded parts of the new mechanical turmoil. It is a lot harder to quantify or measure the potential business rates. What kind of new occupations will it present? What does a Smart Factory worker need the ability to fight in a routinely evolving condition, for instance, this? Will such changes lay off various masters? These are the official request to the typical specialist. Industry 4.0 might be the zenith of inventive progress in gathering, anyway despite all that it appears as if machines are expecting power over the business. Along these lines, it is essential to explore this approach furthermore to have the ability to achieve conclusions on the economics of work later on. Future is not far to prepare for. Given the possibility of the business, it will introduce new occupations in colossal data examination, robot experts, and a massive piece of mechanical originators. While endeavoring to choose the kind of occupations that Industry 4.0 will present or need more work in, BCG has appropriated a report subject to gatherings with 20 of the business' masters to show how 10 of the most crucial use cases for the foundation of the business will be influenced.

Enormous Data-Driven Quality Control: In structuring terms, quality control goes for diminishing the unavoidable assortment between items ${ }^{6}$. Quality Control depends to an extensive degree on quantifiable systems to demonstrate whether an unequivocal component of a thing, (for instance, size or weight) is changing in a way that can be seen for instance. Such methods depend for the most part on social affair progressing or recorded data 
concerning the thing. Regardless, since Industry 4.0 will rely upon large data for that, the prerequisite for quality control masters will reduce. On the contrary side, the enthusiasm for colossal data specialists will increase.

Robot-Assisted Production: The entire commence of the new business depends on the sharp contraptions having the ability to work together with the enveloping condition. This suggests masters who help creation, (for instance, packaging) will be laid off and be displaced with sharp devices equipped with cameras, sensors, and actuators that can perceive the thing and after that pass on the essential changes for it. This way, the enthusiasm for such experts will drop and will be replaced with "raobot facilitators".

Self-Driving Logistics Vehicles: One of the most basic central purposes of enhancement is transportation. Drafters use straight programming strategies, (for instance, the Transportation Model) to utilize the use of transportation. In any case, with self-moved vehicles, and with the assistance of significant data, such enormous quantities of drivers will be laid off. Besides, having selfpushed vehicles mulls over impediment-free working hours and higher utility.

Creation Line Simulation: While the necessity for progression for transportation rots, the prerequisite for mechanical fashioners (who commonly tackle enhancement and reenactment) to recreate arrangements lines will increase. Having the advancement to reenact creation lines before establishment will open up occupations for mechanical designers invest enormous energy in the cutting edge field.

Prescient Maintenance: Having splendid devices will empower producers to anticipate dissatisfactions. Splendid machines will have the ability to in like manner self-sufficiently care for themselves. Along these lines, the number of ordinary upkeep masters will drop, and they will be displaced with even more in truth taught ones.

Machines as a Service: The new business will in like manner empower makes to move a machine as an organization. This infers rather than pitching the entire machine to the client, the machine will be set-up and kept up by the producer while the client abuses the organizations it gives. This will open up occupations in help and will require advancement in arrangements.

\section{References}

1. Kugley S, Wade A, Thomas J, Mahood Q, Jorgensen AMK, Hammerstrom K \& Sathe N. Searching for Studies: A Guide to Information Retrieval for Campbell. Campbell Systematic Reviews. 2016.

2. Landes DS. The Unbound Prometheus: technological change and industrial development in Western Europe from 1750 to the present. Cambridge University Press. 2003. https://doi.org/10.1017/CBO9780511819957

3. Scheer AW. Industry 4.0: From Vision to Implementation. Whitepaper. 2015.

Schwab, K. The Fourth Industrial Revolution. In the World Economic Forum. 2016.

Stentoft J, Olhager J, Heikkila J \& Thoms L. Manufacturing back showing. 2016.

4. Swink M \& Nair A. Capturing the competitive advantages of AMT:Design-manufacturingintegrationasacomplementary asset. Journal of Operations Management. 2007. https://doi.org/10.1016/j.jom.2006.07.001

5. Zhang Z, Liu S, Tang M. Industry 4.0: Challenges and Opportunities for Manufacturing Industry. Technical Gazette. 2014.

6. McKinsey Global Institute. Manufacturing the future: The next era of global growth and innovation, November. 2012. 